\title{
Understanding, Communication, AND CONSENT
}

\author{
JOSEPH MILLUM \\ Clinical Center Department of Bioethics and Fogarty International Center, National \\ Institutes of Health \\ DANIELLE BROMWICH \\ Department of Philosophy, University of Massachusetts Boston
}

\begin{abstract}
By giving consent, competent adults can permit acts that would otherwise be rights violations. In order to give valid consent a person must be capable of autonomous decision-making and her consent must be proffered voluntarily. However, competence and voluntariness are insufficient. The person who gives consent must also understand what she is authorizing. In this paper we develop an account of the understanding requirement for valid consent. We argue, contra existing accounts, that the content of the understanding requirement is minimal. Valid consent requires that the person proffering it understand just three things: (1) that she is giving consent; (2) how to exercise her right to give or refuse consent; and (3) to what she is being asked to consent. To meet the third condition, the profferer of consent must share an understanding with the recipient of consent of how the normative boundaries between them will be redrawn. This mutual understanding is achieved through successful communication. The content of what is successfully communicated can be analyzed in terms of implicatures: the overlap in utterer- and audience-implicature contains what both parties have communicated to each other and hence mutually understand.
\end{abstract}

Misconceived Consent: Miguel has stage IV lung cancer. He has nearly exhausted his treatment options when his oncologist, Dr. Llewellyn, tells him about an experimental vaccine trial that may boost his immune response to kill cancer cells. Dr. Llewellyn provides Miguel with a consent form that explains why the study is being conducted, what procedures he will undergo, what the various risks and benefits are, alternative sources of treatment, and so forth. She even sits down with him, care-

Contact: Joseph Millum <joseph.millum@nih.gov> \& Danielle Bromwich < danielle.bromwich@umb.edu> 
fully talks through the most important points, and gives him time to ask questions. Though it is a Phase 1 study and the chance that he will benefit is very low, Miguel happily agrees to take part. A week later, after the first experimental injection, she asks him if he is worried about the risks. "Risks?" he asks. "I'm sure this is safe-you're a doctor, after all!"

First Sex: Ezra is a virgin but is eager to have sex. His partner, Daria, happy to be his first, starts kissing him one afternoon and one thing leads to another. "Are you sure this is what you want?" she asks. "Definitely," he replies. Afterwards, Ezra wonders what all the fuss is about-that definitely wasn't the magical experience that the movies had led him to expect.

As competent adults, we have rights over our bodies and property, and these rights correlate with duties of others not to interfere. By giving valid consent, we can permit acts that would otherwise be rights violations, such as allowing a dentist to pull an infected tooth or authorizing a broker to sell our shares. In order to give valid consent a person must be capable of autonomous decisionmaking and her consent must be proffered voluntarily. However, competence and voluntariness are not normally considered sufficient for valid consent. The person who gives consent must also understand what she is authorizing. But the content of this understanding requirement is mysterious.

It might seem obvious that in order to give valid consent the profferer of consent just needs to understand what she is consenting to. But what does this entail? The profferer cannot be expected to understand everything about the act in question. We never know all the true propositions about a proposed act. For example, no one knows everything about the experimental vaccine Miguel receives in Misconceived Consent. The very purpose of the trial is to discover new facts about its safety and efficacy. Yet we typically think it is possible to give valid consent to receive an experimental drug. First Sex illustrates another type of ignorance. Ezra does not know what it is like to have sex, so it is hard to say in what sense he understands what he is consenting to at all. ${ }^{1}$ Yet we think his consent is valid.

In the face of such cases, it might be tempting to think that the profferer could give valid consent without understanding anything about the act being consented to. Once we have ensured that the person giving consent is capable

1. "The paramedic riding in the back ... had never seen a gunshot wound. He kept asking what it felt like? dull or sharp? an ache or burn? My head was spinning and naturally I could give him no kind of coherent answer but I remember thinking dimly that it was sort of like the first time I got drunk, or slept with a girl; not quite what one expected, really but once it happened one realized it couldn't be any other way" (Tartt 2004: 543). 
of making his own decisions and acts free of the illegitimate control of others, maybe there is nothing else to valid consent. ${ }^{2}$ However, if we are to make sense of our practice of giving and receiving consent, such a view cannot be correct. Were it possible for someone to give valid consent to an act without understanding anything at all about what he was doing, we would not be able to distinguish between him giving consent to the act proposed and him doing something else entirely. If Daria thinks that she is proposing to kiss Ezra and he thinks that he is being asked whether he is warm enough, his affirmative response is not even a token of consent.

We cannot be completely ignorant of what we are consenting to, but, on the presumption that valid consent is possible, we cannot be required to understand everything about the act either. What, then, do we need to understand in order to give valid consent? In this paper we argue that the content of the understanding requirement is minimal. Valid consent requires that the person proffering it understand: (1) that he is giving consent; (2) how to exercise his right to give or refuse consent; and (3) to what he is being asked to consent. This account both preserves our practice of giving consent in the face of skeptical worries about the possibility of valid consent, and provides necessary and sufficient conditions for adequate understanding that can be applied to contested cases, like Misconceived Consent.

In the first part of the paper we argue that these three conditions are necessary for valid consent. The key challenge is to specify what it means to understand what one is consenting to, that is, the third condition. We argue that knowing what one is consenting to means that the profferer and recipient of consent must share an understanding of how their normative relationship has been changed by the token of consent. Shared understanding is best analyzed in terms of the conditions for successful communication, which we illustrate using the tools of Gricean conversational implicature. The content of what is successfully communicated can be analyzed in terms of implicatures: the overlap in uttererand audience-implicature contains what both parties have communicated to each other and hence mutually understand. In the second part of the paper we consider whether the three conditions are sufficient to meet the understanding requirement for valid consent. The most plausible further conditions cite the in-

2. Gopal Sreenivasan comes close to endorsing such a view on the grounds that the purpose of the understanding requirement is to afford a competent adult the opportunity to protect his interests. In the context of consent to clinical research, Sreenivasan argues that when a trial is properly and independently assessed and when it has a favorable risk-direct benefit ratio, the trial is in the participant's clinical interests anyway. He concludes, "If reliable independent judgment of a trial's risk-direct benefit ratio is favorable, an individual's ignorant decision to participate should not be treated any differently from an ignorant decision not to participate" (Sreenivasan 2003: 2017). However, even in these cases, Sreenivasan accepts that valid consent cannot be entirely ignorant. For critical analysis of Sreenivasan's argument, see Bromwich (2015). 
terests or the preferences of the person proffering consent. We argue that where these factors are relevant to the validity of consent there are superior explanations of their relevance that do not entail that they must also be understood.

\section{What Needs to Be Understood for Valid Consent?}

\subsection{Validity}

At the outset, it is helpful to get clear on what validity is and why we focus on it. As we use the term, valid consent is consent that successfully waives a right. More formally:

P's act A constitutes valid consent to $\varphi$ iff by A-ing, $\mathrm{P}$ waives her right against $\varphi$

So, for example, if Ezra gives valid consent to Daria kissing him by saying "Yes," then his speech act has had the effect of waiving his right against Daria that she not kiss him.

This definition does not tell us much that is useful for working out whether a token of consent is valid. It naturally prompts the question of under what conditions P A-ing successfully waives P's right against $\varphi$. Articulating those conditions is the job of a philosophical account of consent of which this paper is just a part. ${ }^{3}$ However, the definition does help to explain how validity relates to other relevant normative concepts. For example, the fact that Daria had good reason to believe that Ezra's consent was valid explains why it was permissible for her to kiss him. If she had reason to think that he did not understand what she had requested (or lacked the cognitive ability to give consent or had done so under duress), then she ought not to proceed because she would have reason to think that doing so would violate Ezra's rights. The question of whether consent is valid is therefore foundational. We seek valid consent because it is morally transformative. We judge actions whose permissibility depends on consent according to whether the person acting had sufficient reason to think that the moral transformation had been effected.

\subsection{Three Necessary Conditions}

As we noted above, one clear limit to what the profferer of consent can be ignorant of is given by the information that is needed to distinguish between him

3. The other key parts being an analysis of what constitutes the capacity to give consent and under what conditions a token of consent is voluntarily given. 
giving consent and him doing something else. First, then, the person proffering consent must understand that he is giving consent, not engaging in some other speech act. ${ }^{4}$ Second, he must understand how to exercise his autonomy right in order to give or refuse consent. For example, he must understand that putting his signature on this line, with that person watching, and so forth, signifies that he has given consent. If these two conditions are not met, the words or gestures through which he tokens consent cannot be ascribed to him as an intentional act under the description giving consent. These are basic conditions on the successful performance of any speech act. 5

Third, however, it must be possible to distinguish between different acts to which the person might be agreeing. It must be possible, for example, to distinguish between an individual consenting to lend someone his car or his bike, to have sexual relations or just a kiss, and so forth. Thus, where the requestor of consent proposes to the profferer of consent that she $\varphi$, to successfully consent he must understand that she is going to $\varphi$, not do something else. The person granting consent must understand what he is consenting to.

To give valid consent, the profferer must fulfill all three conditions. What is required to fulfill the first two conditions - understanding that one is giving consent and what actions signify consent-is relatively straightforward. But what is required to fulfill the third condition is more perplexing.

\subsection{A Puzzle}

For any act there are indefinitely many ways in which it could be accurately characterized. For example, consider drawing someone's blood, a common act that requires a clinician to obtain her patient's consent. This act could be described in the most general of ways - "Doing something to someone's body" - or with great precision - "Moving NNE at $3 \mathrm{~km} / \mathrm{h}$, the tip of the steel cylinder first touches the epidermis at 15:04 ..." The description could be limited to the act-"Drawing your blood" - or include its purpose or consequences - "Drawing your blood in order to culture stem cells with the risk of causing bruising, pain, and infection." Some descriptions of the act are at levels of detail that neither party to the transaction might be able to articulate or understand, such as descriptions of what will be happening at the molecular level. The condition that the person giving consent must understand what act he is consenting to therefore prompts the question, what is the right way to characterize the act?

4. We have an inclusive view of speech acts. They can be direct, such as the imperative, "Get off my foot", and indirect, such as the indirect imperative, "You seem to be standing on my foot" (Searle 1975). Speech acts can also be verbal, implied by what is verbalized, or non-verbal.

5. See Grice (1957). Note that some writers separate out an intention condition from the understanding condition (Faden \& Beauchamp 1986: 241-262). 


\subsection{Resolving the Puzzle}

To work out the right level of description, we must return to the point of consent. Valid consent to an act transforms it from one which would be a rights violation to one which is not. It does this by redrawing the rights and responsibilities of the two parties to the consent transaction. ${ }^{6}$ This redrawing is usually precise. Consent changes the parties' rights and responsibilities only with respect to one another and only with respect to the act in question. In giving consent to my doctor drawing my blood, for example, I do not thereby give consent to anyone else sticking a needle in my arm, and I do not thereby permit her to intrude on my body in other ways, such as by hugging me.7 Thus, the profferer of consent must understand how the requestor of consent is proposing that they redraw the normative boundaries between them. No more and no less. ${ }^{8}$

We can illustrate this with variations on the blood draw case. Suppose a doctor asks, "May I draw your blood?" and her patient agrees. If each understands that this involves inserting a hypodermic needle into his arm then his agreement would give her permission to insert a hypodermic needle into his arm and no more. She may not insert some other type of needle, she may not insert it elsewhere, and she may not do anything else with it that is not part of drawing blood.

Their mutual understanding about what is proposed translates directly into mutual understanding about how their normative relationship will be changed by his consent. In effect, her asking, "May I draw your blood?" is the same as her asking, "May I insert a hypodermic needle into your arm and remove blood?" which is the same as her asking "Could you make it the case that I am permitted to insert a hypodermic needle into your arm and remove blood?" and his consent has that normative effect.

Suppose, instead, that he does not realize that a blood "draw" involves a needle and the removal of blood; he thinks she is an artist in her spare time and she is planning an imaginative sketch of his bodily fluids. His agreement will then fail to give her permission to proceed because they do not share an understanding of what it means to draw blood. Specifically, they do not share an understanding of the aspects of drawing blood that constitute rights violations if carried out without permission-inserting a needle into a vein and removing blood.

6. Our understanding of the nature of consent owes a substantial debt to the discussion in Ripstein (2009).

7. This is not to rule out the possibility of a single act of consent waiving someone's rights with respect to multiple parties or, indeed, to collective entities whose constituent members are not known to the profferer of consent.

8. No more because they must only have mutual understanding of how the rights and responsibilities of each will be altered by the granting of consent. No less because the scope of what is consented to will be constrained by how much they share understanding of what will be done. 
Capturing the understanding requirement in terms of how the normative boundaries between the two parties are to be redrawn explains how consent is possible in cases like First Sex. Ezra has a right against Daria that she not have intercourse with him without his permission. This right is derived from his more general right to bodily integrity, which he can waive in very specific ways. In this case, he can waive the right with regard to how and where she touches him with her body. All he therefore needs to understand is how and where she is proposing that their bodies touch. This much he can understand, even if he has no idea what the sensation of sex will be like.

This analysis gives us a rough characterization of the third condition. But there are still cases in which it is unclear whether the profferer and requestor of consent share an understanding of how the normative boundaries between them will be redrawn. In the remainder of this section, we use one such case to make our characterization of the third condition precise.

\subsection{A Hard Case}

The right level of description of an act for the purposes of consent is the level that describes the way in which the normative boundaries between requestor and profferer will be redrawn. However, the following, slightly more complicated case presents a challenge for this analysis.

Big Needle. Dr. Al-Bishi wants to biopsy Vincent's arm muscle. This, she informs him, will involve inserting a needle into his arm and harvesting a small amount of muscle tissue. Dr. Al-Bishi gives Vincent the option of looking at the equipment beforehand, and the needle is accurately described on the consent form she has him sign. However, Vincent does not take advantage of this opportunity and so remains unaware that the needle used for this muscle biopsy (a gun needle) will be much larger than the needle used for a standard blood draw (a hypodermic syringe), which is the needle he is imagining. Indeed, it is wide enough that were he to know about it, he would not agree to the procedure. "May I insert a needle into your arm?" Dr. Al-Bishi asks him and, thinking of the hypodermic syringe, he agrees. Already squeamish about needles, Vincent keeps his head resolutely turned away from the moment the doctor comes back into the room, and so he does not realize his mistake until she sticks him.

Assuming that Dr. Al-Bishi had no reason to think that Vincent was ignorant about the needle she is going to use, it is plausible that she did nothing 
wrong by proceeding. 9 But what should we say about the validity of his consent?

\subsection{Analysis of Big Needle}

On one interpretation of what we have argued so far, Vincent's consent is valid, since he understands what a needle is, and would, if pressed, agree that the gun needle is a type of needle. We might think that he has agreed to a redrawing of the normative boundaries between Dr. Al-Bishi and himself that includes permission to insert anything that falls under his concept of needle. On another interpretation, his consent to the biopsy is invalid, because he still did not know what would be stuck into his arm. He did not take himself to be redrawing the normative boundaries between them in a way that gave permission for that! Thus, there is a sense in which Vincent understands what will happen to him and a sense in which he does not. Our original conundrum about the right way to describe the act requiring consent arises again.

We can deepen this challenge by exploring two natural ways to characterize mutual understanding. On the first view, it is a matter of picturing the same thing. This implies that Dr. Al-Bishi and Vincent did not have mutual understanding. After all, the needle in Vincent's head is not the same needle as the one in his doctor's. But this cannot be the sort of mutual understanding that is required for valid consent, since successful communication would be all but impossible if it required that the parties involved literally had to be imagining the same thing. Suppose Freya texts Massimo, "I'm outside waiting in my car." Massimo imagines that she drives a red Corvette and so when he goes outside he is surprised to discover Freya's car is a white Mini. His surprise would not warrant the claim that Freya had failed to communicate with him. The picture in the head model is mistaken.

An alternative view of mutual understanding entails that Vincent did understand what Dr. Al-Bishi proposed. On this view, two people have mutual understanding just in case each grasps the intension of the terms that are used in their communication. Thus, if Vincent knows what a needle is, such that he would agree that the gun needle falls under the concept of needle, then he understood what Dr. Al-Bishi was proposing to do. But this is not quite right, either. Vincent might agree that a hypodermic syringe needle and a gramophone needle both fall under the same concept-both are called needles because they are thin cylinders with pointed tips - but he certainly has not agreed to anything involving a gramophone needle.

9. See Section 3.2 for a discussion of how consent can be morally transformative even if invalid.

Ergo •vol. 5, no. 2 2018 
We think this second interpretation is actually correct, just not in its unrestricted form. Mutual understanding is not simply a matter of agreeing on the intension of the terms used in the proposal. It is also a matter of recognizing the context in which the proposal is made and what that includes and excludes. As H. P. Grice noted, a remarkable feature of our everyday conversation is that, as speakers, we often succeed in conveying what we mean even though the words we use do not literally mean what we say. When Dr. Al-Bishi asks, "May I insert a needle into your arm?" her patient understands her to conversationally implicate "medical needle", even though she does not say so explicitly.

According to Grice, what explains our ability to convey and identify communicative intentions is the presumption that there are rational constraints on our conversational exchanges (Grice 1989). ${ }^{10}$ We are not mind readers, and so we must presume that certain conversational maxims are being observed. ${ }^{11}$ To illustrate, consider Dr. Al-Bishi's question. To conversationally implicate "May I insert a medical needle into your arm?" by asking, "May I insert a needle into your arm?", Vincent must presume-and Dr. Al-Bishi must presume that he presumes - that she is being cooperative and, as such, is observing certain conversational maxims (see Grice 1989: 26-27). Their conversation takes place in a medical setting and concerns an imminent medical procedure; it would be highly uncooperative of Dr. Al-Bishi to be referring to anything other than a medical needle when she asks the question. ${ }^{12}$

However, still more must be done in order to specify what has been successfully communicated. The proper taxonomy of implicature is richer than standard readings of Grice would have us believe. In addition to conversational implicature, Jennifer Saul (2002) introduces the concepts of utterer-implicature and audience-implicature. Utterer-implicatures are claims that the speaker attempts to conversationally implicate, though she might fail to do so. ${ }^{13}$ In an attempt to reduce Vincent's anxiety, suppose that Dr. Al-Bishi shows him her latest embroidery project. She knows that he is an avid crafter and as she talks him through the new stitch she has mastered, he visibly relaxes. Seizing the opportunity, she

10. It should be noted that our argument in this paper turns on the claim that shared understanding is best analyzed in terms of successful communication, rather than any specific feature of the theory of communication we use to illustrate this claim. Our argument could be reconstructed equally well using an alternative theory of communication, such as Stalnaker's "common ground" (Stalnaker 2002).

11. For illustration and critical discussion, see Bach (2012).

12. In Gricean terms, it would involve violating one of the Quantity maxims: "make your contribution as informative as is required (for the current purposes of exchange)." If she is referring to a non-medical needle, her contribution is not as informative as is required since it is reasonable to assume that she is only referring to a medical needle. For similar reasons, she would also violate the Relation maxim: "be relevant" (Grice 1989: 26-27).

13. E.g., if her audience actually does not need to attribute the claim to her in order to make sense of her utterance. 
asks, "May I insert a needle into your arm?", intending to proceed with the biopsy. In this unlikely scenario, Dr. Al-Bishi utterer-implicates medical needle, but that implicature might fail to receive uptake from her audience because a non-medical needle is salient. Audience-implicatures are claims that the audience takes the speaker to be implicating, though, again, she might not be so doing. On seeing Vincent relax, Dr. Al-Bishi might decide to make a joke. She asks, "May I insert a needle into your arm?" referring to the sewing needle she is holding. But if Vincent takes her to actually be referring to a medical needle he will have audience-implicated that request despite her intentions. Saul concludes, "A claim which is both utterer-implicated and audience-implicated ... will be one which is successfully communicated" (2002: 243). ${ }^{14}$

We can make use of this Gricean model to work out what is communicated in requests for consent. First, the conversational maxims will rule out some of the more outlandish literal interpretations of the words used by the requestor of consent. For example, they will rule out the interpretation of "needle" to mean "gramophone needle." However, second, successful communication does not require that the requestor and the profferer be imagining the same thing. For example, the color of a car is not usually utterer- or audience-implicated by someone saying "I'm outside waiting in my car" - we would have to tell a fanciful story in order to make such an implicature plausible.

Third, successful communication requires that both parties implicate the same sub-category of the concept that a label is being used to refer to. The same concept-needle, meaning a thin cylinder with a pointed tip-may include as sub-categories gramophone needles, craft needles, pine needles, medical needles, and so forth. These sub-categories may themselves be divided up into more fine-grained sub-categories. So craft needles include knitting needles and sewing needles. Medical needles include hypodermic needles, gun needles, and surgical needles. In turn, these sub-categories can be divided into even more fine-grained sub-categories. The label "needle" can be accurately applied to all of them.

In the right context, it will not be necessary for a speaker to say explicitly which of these sub-categories she means when she just says "needle." For example, if two nurses are discussing drawing someone's blood and one asks the other to pass a "clean needle," then he clearly means a hypodermic needle, not a gun needle. If the attending physician tells them to "collect all the needles" from a drawer containing both hypodermic and gun needles, then she clearly means that both types of needle should be collected. In the first case, the nurse uttererimplicated \{hypodermic needle\} and his colleague audience-implicated the same. In the second case, the doctor utterer-implicated \{medical needle\} and the

14. Note that what matters for successful communication - and so for the understanding necessary for valid consent-is what is actually utterer- and audience-implicated. This is a separate matter from what ought to be implicated by the parties involved. 
nurses audience-implicated the same. Depending on the context, the same word, referring to the same broad concept, can be utterer- or audience-implicated to be referring to a more or less fine-grained sub-category of the concept.

We are now in a position to return to Big Needle. If Vincent audienceimplicated \{medical needle\} and Dr. Al-Bishi utterer-implicated \{gun needle\} then Vincent has given consent to being stuck with the gun needle, since that is a form of medical needle. ${ }^{15}$ If Vincent audience-implicated \{hypodermic needle\} and Dr. Al-Bishi utterer-implicated \{medical needle\} then Vincent will have given consent to being stuck with a hypodermic syringe, though not a gun needle. And if Vincent audience-implicated \{hypodermic needle\} and Dr. Al-Bishi utterer-implicated \{gun needle\} then communication has failed and Vincent has not given valid consent to be stuck with anything.

\subsection{Objection and Reply}

One might take issue with the claim that Vincent gives valid consent to being stuck with a gun needle upon audience-implicating "medical needle". Suppose he lacks the fine-grained concept of a gun needle. How can Vincent and Dr. AlBishi achieve mutual understanding of the proposal when he does not have the concept of the needle-type that she is proposing to insert into his arm?

The answer is that mutual understanding is achieved through successful communication, and that is still possible here. Imagine the gun needle lies on a tray beside Vincent. As Dr. Al-Bishi enters the room, she asks, "Is the medical needle on the tray?" As Vincent looks, he may simultaneously nod and think, "Yikes, I had no idea they made medical needles like that!" His mastery of the general concept of a medical needle enables him to grasp and accurately answer her question, even though he lacks the more fine-grained concept of a gun needle. His surprise is no more puzzling than Massimo's surprise at the white Mini: mutual understanding is no more a matter of picturing the same needle than it is picturing the same car. It is a matter of successful communication. And that is possible even when one party has a layperson's grasp of the concept, while the other has an expert's.

In many ways, this case is reminiscent of First Sex. If Vincent audienceimplicates "medical needle" while lacking the concept of a gun needle, the experience of having his muscle biopsied may be very different to how he imagined

15. Vincent does not have to infer that gun needle is being referred to. But he would have to infer that medical needle is being referred to, rather than some more specific sub-type that rules out gun needles. Vincent might, of course, have a layperson's conceptualization of different types of medical needle, such that he would not label them "hypodermic," "gun needle," and so on. But for the purposes of determining whether communication has been successful, such conceptualizations are no less valid than those of the expert. 
it would be. But that does not give us reason to doubt the validity of his consent. We frequently consent to acts that turn out different than we imagined. Ezra might never have had a sensation quite like having sex with Daria. Despite lacking this experiential understanding, his consent was valid because he understood that he was authorizing her to touch his body with hers in specific ways. Perhaps Vincent would not have agreed to the procedure had he known that the needle would be that big or that the muscle biopsy would feel like that. But he would agree that a gun needle is a medical needle, and that is what he authorized Dr. Al-Bishi to insert into his arm.

\subsection{Summary}

What needs to be understood in order to give valid consent? The profferer needs to understand: (1) that he is giving consent, (2) how to exercise his right to give consent, and (3) what he is consenting to. The right way to describe what he consents to is in terms of mutual understanding between him and the recipient of consent regarding how his rights claims against her are to be changed. This mutual understanding is achieved through successful communication between the two parties. Our analysis of Big Needle implies that the most fine-grained subcategories of the concepts used in the consent exchange that are both audienceimplicated and utterer-implicated are the ones with respect to which the normative relationship between profferer and recipient has been changed. ${ }^{16}$

\section{Are these Necessary Conditions for Understanding also Sufficient?}

We made a bold claim in Section 1.4: to give valid consent to $\varphi$, the profferer need only understand that he is giving consent, how to give consent, and how the normative boundaries between profferer and requestor will be redrawn so that they permit $\varphi$. This claim requires defense. After all, many people think that a lot more needs to be understood in order for consent to be valid. ${ }^{17}$ In this section, we consider two views that imply that the understanding requirement

16. There will remain, of course, an epistemological challenge in cases when it is not clear whether what was utterer-implicated was also audience-implicated, but this is to be expected. Sometimes we can only discover by further inquiry whether or not someone understands what we are saying. And sometimes it will be the case that the requestor of consent innocently takes as valid a token of consent that was, in fact, invalid because there was a crucial misunderstanding. Any account of consent should leave space for such possibilities.

17. E.g., in the literature on the ethics of clinical research with human subjects, where the content of the understanding requirement has been explicitly articulated in the greatest detail, it is generally assumed that potential research participants must understand the risks and purpose 
contains additional content - the interests and inducements views - and argue that they are mistaken. ${ }^{18}$ Since these views present the most plausible grounds for additional components of the understanding requirement for valid consent, we tentatively conclude that the three necessary conditions we have identified are also sufficient. ${ }^{19}$

\subsection{The Interests and Inducements Views}

The first view that implies more than the three components must be understood is the interests view. According to this view, in order to give valid consent the profferer must understand all the true propositions about the proposed act that are relevant to his interests (Wendler \& Grady 2008: 205-206). Since the risks of an act are relevant to the profferer's interests, this view implies that they ought to be understood. The second view is the inducements view. According to this view, in order to give valid consent the profferer must understand all the true propositions about the proposed act that would dispose him one way or another with regard to his decision about whether to consent (Faden \& Beauchamp 1986). ${ }^{20}$ In some cases, the risks of the act or the purpose of the act are relevant to someone's decision about whether to give or refuse consent; in such cases, this view implies that risk or purpose ought to be understood, whether or not the person's interests would be affected. For both of these views, it is straightforward to see the sort of explanation that they could offer for the content of the understanding requirement that they prefer. For example, a proponent of the interests view might think that the function of consent is to allow an individual to advance her interests. This would explain why the content of the understanding requirement is comprised of those facts about an act that are relevant to the interests of the person giving consent. Alternatively, a proponent of the inducements view might think that the function of consent is to allow an individual to act according to her preferences and values. In that case, she could explain why

of the act(s) requiring consent among other relevant facts. See, e.g., World Medical Association (2013), Council for International Organizations of Medical Sciences (CIOMS) (2016).

18. For a complementary critique of these views, see Bromwich and Millum (2015: 209-212). The focus in that paper is on the disclosure requirement, which functions to protect voluntariness, rather than on the understanding requirement.

19. In this section we consider these views as potential accounts of the understanding requirement for valid consent, in general. In Section 3.3, we address the potential objection that the requirements for "informed consent" in clinical care and research are different than those for valid consent in other domains.

20. It is noteworthy that Faden and Beauchamp supplement their inducements view with a requirement that there be shared understanding between the recipient and the profferer of consent about what is being authorized (Faden \& Beauchamp 1986: 298-336). 
the content of the understanding requirement is those facts that would dispose the person giving consent one way or the other.

To illustrate how these views are problematic, we return to Misconceived Consent. Miguel has stage IV lung cancer and is being asked by his oncologist, Dr. Llewellyn, to consent to an experimental injection. For the purposes of illustration, we focus on her explanation of the injection's risks, assuming that all other requirements for valid consent are satisfied. Consider the following: ${ }^{21}$

Unknown Risk: Dr. Llewellyn knows that the experimental injection has risks $\mathrm{A}$ and $\mathrm{B}$. However, unknown to her, it also has risks $\mathrm{C}$ and D. No scientist knows or has publicly hypothesized C or D. Dr. Llewellyn discloses that the experimental injection has risks $\mathrm{A}$ and $\mathrm{B}$, and that there may be further unknown risks. Miguel consents to the injection.

On the wide reading we have given, the interests and inducements views imply that Miguel's consent is invalid. He is ignorant of facts that are relevant to his interests and likely dispositive: the existence of risks $C$ and D. However, this interpretation of Unknown Risk is counterintuitive. We are frequently asked to consent to acts whose risks are unknown. ${ }^{22}$ If ignorance of such facts renders consent invalid, then valid consent is impossible.

To avoid this absurdity, the views could be narrowed. A natural modification would be to say that to give valid consent, the profferer must understand all and only those facts known to the requestor of consent and which are relevant to his interests or would be dispositive. On these modified views, Miguel's consent is valid in Unknown Risk because the risks are unknown to both parties, but it is invalid in cases like the following:

Undisclosed Known Risk: Dr. Llewellyn knows that the experimental injection has risks A, B and C. Once again, she does not know about risk D and she is not negligently ignorant. She discloses A and B, but withholds C. Miguel consents to the injection.

Read narrowly, the interests and inducements views give the intuitively correct responses to Unknown Risk and Undisclosed Known Risk. The challenge for proponents of these views is to explain the difference between them. In both cases, the profferer of consent is a competent adult, the requestor of consent

21. Compare Bromwich and Millum (2015: 201-202).

22. This is especially evident when giving consent to receive an experimental drug, but it is also generally true of other cases of consent. We are never in a position to know every fact about an act we consent to that might be relevant to our interests or to our decision whether to give or refuse consent. 
discloses the same information about the risks of the act requiring consent, the profferer understands the information, and he voluntarily gives consent. In neither case are all the true propositions about the act's risks known. The modified views imply that his consent is valid only in the first case because in that case he understands the same facts as Dr. Llewellyn. His consent is invalid in the second case because she knows more than him about the injection's risks. But what fact about Miguel's interests or inducements could explain why his consent is invalid when his understanding does not track hers? After all, his interests are equally protected in both cases and his ability to decide on the basis of his preferences is the same.

We think that searching for the normative difference between the two cases in what the profferer of consent understands is a mistake. We agree that Miguel's consent is invalid in Undisclosed Known Risk, but it is not because he fails to understand risk C, it is because Dr. Llewellyn does not disclose it. In Undisclosed Known Risk, Miguel is ignorant of risk C because Dr. Llewellyn voluntarily withholds this fact from him, despite her having reason to believe that he would likely find it relevant to his enrolment decision. By withholding this information from him and thereby disposing him to decide one way rather than another, Dr. Llewellyn exercises illegitimate control over Miguel's decision. ${ }^{23}$ It is this control that undermines the validity of his consent. No such control is exerted in Unknown Risk because Dr. Llewellyn does not know about risk $C$ either. She therefore cannot influence Miguel's decision by providing or withholding information about $C$.

Note that nothing in this control view of disclosure implies that Miguel must understand risk $\mathrm{C}$ in order to give valid consent. Whether or not the person requesting consent exerts illegitimate control depends on what she does with the information at her disposal, not what the profferer of consent does with it. ${ }^{24}$ If she has reason to think that a piece of information would be relevant to his decision, that gives her a reason to disclose it, and to disclose it in a way that allows him to use it in his decision-making. He may or may not use it; but it is up to him, not her.

A final variant on the case illustrates the difference in explanatory power between the control view of disclosure and the alternative views of understanding we have criticized.

23. For analysis of the ways in which inappropriate disclosure can constitute illegitimate control see Bromwich and Millum (2015: 213-219).

24. One might retain the intuition that something is wrong when the profferer of consent fails to understand what has been disclosed. And sometimes something is wrong. E.g., the requestor of consent will sometimes have a professional duty or a duty of beneficence towards the profferer of consent that entails a duty to help him make a good decision. This is plausibly true of physicians with respect to their patients. We only claim that the profferer of consent can give valid consent when he fails to understand some of the facts that ought to be disclosed to him. We explore such a case in Bromwich and Millum (2015: 207-208). 
Unusual Preferences. Dr. Llewellyn knows that the experimental injection has risks A and B and discloses these risks to Miguel. She also knows that the principal investigator of the study has a bushy beard but does not tell Miguel because it does not occur to her that it might be relevant. In fact, beards make Miguel extremely anxious and he would have refused to be part of the study if he had known. Miguel consents to the injection.

The fact that the principal investigator has a beard is relevant to Miguel's interests and would be dispositive for him. The modified interests and inducements views would therefore have to say that Miguel's consent is invalid in this case. Again, this conclusion seems implausible: Miguel's consent is clearly valid. Again, the accounts could be modified to take such cases into account. For example, we might amend the inducements view to say that to give valid consent, the profferer must understand only those facts known to the requestor of consent that the requestor has reason to think would be dispositive and which would be dispositive. But the amendment is ad hoc: it does not help to explain why Miguel's consent is valid, but simply tweaks the view to get the intuitively right result. By contrast, the control view of disclosure can explain why Miguel's consent is valid in Unusual Preferences: Dr. Llewellyn has no reason to think that the information about the principal investigator's beard would be relevant to Miguel's decision and so she cannot use that information to control his decision.

This explanation in terms of disclosure might seem to face challenging cases of its own. Consider, for example, a variant on Undisclosed Known Risk in which Dr. Llewellyn deliberately withholds risk C, thereby attempting to control Miguel's decision, yet Miguel already knows about $C$ from some other source. If Miguel proffers consent, it intuitively seems valid, despite the failure of disclosure. How can we explain this unless Miguel's understanding of risk $C$ is what underlies the validity of his consent?

Here it is important to distinguish between the wrongfulness of an action and its normative effects. While both attempted and successful control over another's decision can be wrongful, only the latter invalidates consent. As a competent adult, Miguel has the right to make his own decisions and a claim against others that they do not make them for him. When Dr. Llewellyn withholds information that she has reason to believe would be relevant to his decision, she ignores a claim against her and acts in ways that are disrespectful to him as an agent. That is why her action is wrong. But she only violates his right to make his own decision when she succeeds in controlling it. Since she does not succeed in this instance, she does not invalidate his consent; she just disrespects him.

The interests and inducements views are the most plausible accounts of the understanding requirement that entail a more substantial content than we have proposed. But these views either make valid consent impossible or are unable to 
explain why more needs to be understood in order for consent to be valid. Cases in which it seems plausible that more information should be provided in order to obtain valid consent are better explained in terms of the relationship between disclosure and control than in terms of what needs to be understood. We conclude that the three necessary conditions we have identified are also sufficient to fulfill the understanding requirement.

\section{Three Objections}

\subsection{Is Communication Necessary for Consent?}

A long-running debate concerns whether consent is purely attitudinal or also performative. Attitudinal views of consent hold that consent is a mental statethey differ as to exactly what mental state-and so it is possible to give consent without signifying that one has done so. ${ }^{25}$ Performative views of consent hold that it necessarily includes a communicative element in addition to whatever mental states are required (Dougherty 2015). We have argued that communication is necessary for mutual understanding and that mutual understanding is necessary for consent. Clearly, then, we have a performative view of consent and our derivation of the understanding requirement is inconsistent with an attitudinal view.

This is an implication that we accept, since we find the arguments against attitudinal views compelling. These arguments have been articulated at length by others. ${ }^{26}$ Here, we have space only to sketch the main considerations that favor a performative view over an attitudinal view.

First, performative views allow for plausible explanations of the function of consent. For example, Tom Dougherty (2015: 244) argues that consent plays the roles of facilitating intimacy, alteration in our normative relationships, and mutual use. These functions of consent require that we be able to hold each other publicly accountable. In turn, this means that consent must involve communication. Similarly, Richard Healey (2015: 359) argues that consent's function is to manage the normative relations between agents and this is only possible if consent is communicated.

Second, and relatedly, attitudinal views do not seem equipped to explain our reactions to certain cases where there has been no outward token of consent. Suppose you ask me to lend you my car in exchange for which you'll play the card game you know I love. I say that I'll think about it. You are very good at

25. See Hurd (1996), Alexander (1996), Alexander (2014).

26. In particular, see Wertheimer (2003), Healey (2015), Dougherty (2015). 
reading me and so accurately predict that I am going to consent. So, you just take the car. I am outraged: "I didn't give you permission to do that!" "But you were going to," you respond. An attitudinal view cannot explain my outrage here. Similar considerations make it hard to see how attitudinal views can draw a principled distinction between actual and hypothetical consent.

Third, an attitudinal view would imply that consent is not a speech act, even though it has the appearance of being one. Instead, on the attitudinal view, there is consent and then, presumably, the speech act of signifying that one has consented (which itself has both mental and performative elements). Not only does this seem unnecessarily complicated - since instead of a single speech act of consenting we now have the act of consenting and the speech act of signifying consent-it makes consent an outlier among moral powers. For other moral powers, such as promising or forgiving, the paradigmatic cases involve speech acts, and it is controversial whether wholly private acts can constitute the exercise of the moral power. For example, can a promise to oneself be morally binding? Can forgiveness that is not expressed release someone from a duty? We think that there would have to be very good reasons for regarding consent as unusual in this way.

Fourth, linguistic intuition heavily favors the performative account. We "give" consent, "grant" consent, and so forth. These terms all seem to implycontra attitudinal views - that there is someone else involved to whom consent is given or granted. Further, we do not normally distinguish consent from signifying consent. Imagine reading in a novel, "She consented to his proposal." The writer need say nothing else for us to infer that there was some communication. Likewise, it is natural to say, "She consented with a nod." No one, to our knowledge, writes sentences like, "She consented and indicated that she had done so by nodding," which would be the full description of what transpired on an attitudinal view. Of course, linguistic intuitions are a highly fallible guide to moral ontology, but it is telling that the attitudinal view is such an unnatural way to describe consent. Insofar as our project involves unpacking a shared understanding of consent, this argues against the attitudinal view. Again, there would have to be very good reasons for adopting a view that required such substantial revisions to our natural ways of speaking.

Finally, we find the reasons that have been given in favor of attitudinal views weak. Larry Alexander, Heidi Hurd, and Peter Westen (2016) present several cases where consent is not communicated but where they think that consent has been given. For example, they describe a case in which a woman wants to have sex with someone but puts up resistance to his advances so as not to appear "easy." When he nevertheless has sex with her they think it clear that she is not wronged-even though he might be as blameworthy as if he raped her-and this is because her mental states constituted consent. Like other critics of attitu- 
dinal views, our intuitions on this case and others like it are very different to Alexander et al.'s. Disagreement about intuitions cannot be resolved by appeal to those intuitions. Alexander et al. also think that absurd implications follow from performative views. For example, such views seem to imply that if the requestor of consent correctly believes the profferer wants her to proceed, but agreement has not been communicated, then there is no valid consent. Again, we find the implication plausible (and, indeed, an interesting result of our account). Again, it would therefore be question begging to use intuitions about these implications to settle the dispute between attitudinal and performative accounts.

\subsection{Is Understanding Necessary for What Matters?}

The second objection challenges our focus on the validity of consent. Sometimes a person's consent is invalid, but the person requesting consent is nonetheless permitted to proceed. Franklin G. Miller and Alan Wertheimer (2010: 85-86) describe a case in which someone mishears a request to borrow a lawn blower for a request to borrow a lawn mower. She would not have agreed to lend the blower, but, given her mistake, tokens consent. Miller and Wertheimer note that, despite the mishearing, the borrower has acted permissibly if he takes the blower. They write:

In Lawn Blower, B understands that she is consenting to allow A to borrow something (as opposed, say, to being kissed), but is mistaken about that which A seeks to borrow. Linguistic intuitions go both ways about these sorts of mistakes and misunderstandings. B might say: (I) "I didn't realize I was agreeing to let you take the lawn blower but I guess I did" or (2) "I didn't agree to let you take the lawn blower, but, given the misunderstanding, you didn't do anything wrong." In our view, the important moral question is not whether (1) or (2) is linguistically correct, but whether A is justified in taking B's lawn blower. (Miller \& Wertheimer 2010: 86)

Thus, it might be argued, what matters is not the validity of consent, but whether or not the relevant moral transformation effected by consent has taken place, and that transformation does not require understanding of what the requestor of consent is asking to do.

We agree that there are clear cases in which a token of consent is invalid even though the person who acts upon it acts permissibly. For example, a doctor might innocently believe that the adult in front of her is capable of making his own decisions about treatment (he is middle-aged, socially able, there is no indication of any mental health problems in his medical record, and so forth). 
Nevertheless, it might be that he suffers from early onset Alzheimer's disease and is now unable to make decisions on his own because unable to retain the relevant considerations in his memory for long enough. If he tokened consent to a procedure, she might be justified in carrying it out. If he really has no idea what is going on, however, we would surely judge his consent invalid. It is not always the case that our intuitions about these cases can go both ways.

However, it would be a mistake to conclude that the validity of consent is of no consequence. Even when the recipient of consent would be permitted to proceed on an invalid token of consent, the validity of consent matters in cases in which it is possible to reverse the effects of proceeding on that token. For example, if the person asking for the lawn blower were asking to own it, rather than just borrow it, then in the case where consent was invalid, the original owner would have cause to ask for its return. ${ }^{27}$ If the consent had been valid, this would not follow. The validity of consent is therefore doing important moral work. ${ }^{28}$

\subsection{Are the Requirements for Consent Universal?}

We have proceeded on the assumption that what is required for valid consent does not vary across the domains in which consent is obtained. Thus, our conclusions about understanding apply to sexual relations, contracts, medical care, and clinical research. In each of these domains, it is necessary and sufficient to meet the understanding requirement for valid consent that the person proffering consent understands that she is giving consent, how to give consent, and what rights she is waiving through this token of consent.

Our assumption of universality might be challenged. In particular, in medical ethics it is common to talk about "informed consent" rather than simply "consent." 29 Given that our examples of alternative and more substantial ac-

27. Whether she would be entitled to the return is a distinct question, which will turn on whether she was culpable for the mistake and whether A would incur costs from returning the blower for which he should not be held responsible. Note, though, that these issues of blame and responsibility are not relevant to the judgment about the validity of consent. Someone can be to blame for rendering an invalid token of consent without it thereby being permissible to proceed upon that token. Our thanks to an anonymous referee for pressing us on this point.

28. It is also important not to mix up cases of invalid consent with cases in which the original token of consent is valid, but the context makes it possible to retract consent. Some cases of valid consent cannot be retracted, such as property transfers or promises. Others can be retracted until a certain point or while the act consented to is taking place. E.g., if Pili agrees to have sex with Ricardo, she can revisit that decision at any point up to the start of coitus, and can refuse to continue at any point during it. In neither case, does her reversal of the decision imply that the original consent was invalid; Ricardo would wrong her only if he proceeded after she rescinded consent.

29. Perhaps the most widely cited text in medical ethics that focuses on consent is Faden and Beauchamp's A History and Theory of Informed Consent (Faden \& Beauchamp 1986). Textbooks and conceptual articles in bioethics almost uniformly refer to "informed consent." 
counts of the understanding requirement draw on the medical ethics literature, it might be argued that we are talking past our opponents. Perhaps "informed consent" is one thing and "valid consent" is another. Our conclusions would then not be relevant to one of the most important contexts in which consent is discussed..$^{30}$

We accept one aspect of this critique. The informed consent process can play multiple roles in medical contexts and our argument here speaks directly to only one of them. For example, institutional and legal requirements for informed consent may protect the interests of patients and research participants (Brock 2008). Without a requirement to ensure that her patient has sufficient understanding to weigh the relevant considerations a clinician might otherwise lead him to make the choice she prefers rather than the one that is best for him. Such concerns are amplified in the context of clinical research, where the goals of the researchgenerating generalizable knowledge-may diverge dramatically from the interests of participants. The informed consent process can also help patients and participants to make better decisions - that is, decisions that are more informed and more in line with the decision-maker's values (Bromwich \& Millum 2017). ${ }^{31}$ It thereby fits with certain ideals of autonomous decision-making.

The set of information that someone needs to understand in order to optimally protect her interests or make a good decision by her own lights is likely to include more than the content of the understanding requirement that we have outlined. Where the informed consent process is intended to fulfill these functions, then, it may entail a more substantive requirement. However, it is indisputable that one core function of the informed consent process, as it is discussed within medical ethics, is to attain what we label valid consent; that is, to ensure that physicians and researchers do not violate the rights of their competent patients and participants by proceeding without permission. For example, Faden and Beauchamp distinguish two senses of "informed consent." The first is an "autonomous action by a subject or a patient that authorizes a professional either to involve the subject in research or to initiate a medical plan for the patient (or both)" (Faden \& Beauchamp 1986: 280).32 This successful authorization is valid consent. Likewise, Neil Manson and Onora $\mathrm{O}^{\prime} \mathrm{Neill}$ argue that the primary function of the informed consent process is to allow patient and participants to waive their rights in specific ways:

We cannot have medical or research interventions unless we permit lim-

30. Our thanks to an anonymous referee for prompting us to address this objection.

31. Others also argue that the informed consent process functions to safeguard trust in medical practice and institutions. See, e.g., Bok (1995), O'Neill (2002), Eyal (2014).

32. The second sense they identify refers to "a legally or institutionally effective ... authorization from a patient or subject," which is quite different (Faden \& Beauchamp 1986: 280). 
ited action that would otherwise constitute a breach of bodily integrity, personal liberty or privacy: informed consent is a way of granting permission for such action. It is not, and certainly not primarily, a way of exercising individual autonomy, however conceived. (2007: 188)33

In short, while the informed consent process in clinical care and research may serve multiple functions, one of the most important is securing valid consent. Insofar as that is its function, we challenge medical ethicists who disagree with our analysis to explain why the understanding requirement should be more substantial in the clinical context than elsewhere.

\section{Conclusions}

What do you need to understand to give valid consent to an act? Our analysis implies that you need to understand exactly three things: (1) that you are giving consent; (2) how to give consent; and (3) to what you are giving consent. To meet the third condition, you must share an understanding with the recipient of consent of how the normative boundaries between you will be redrawn. This mutual understanding is achieved through successful communication. The content of what is successfully communicated can be analyzed in terms of implicatures: the overlap in utterer- and audience-implicature contains what both parties have communicated to each other and hence mutually understand.

\section{Acknowledgements}

For helpful comments on previous versions of this paper, we thank Luke Gelinas, Doug Mackay, Frank Miller, Collin O'Neill, Sergio Tenenbaum, two anonymous referees for this journal, and audiences at the New Scholarship in Bioethics Annual Symposium, the American Society for Bioethics and the Humanities, the Workshop on Gender and Philosophy at MIT, and the Clinical Center Department of Bioethics.

Funding Support: This work was supported, in part, by intramural funds from the National Institutes of Health Clinical Center.

Disclaimer: The views expressed are the authors' own. They do not repre-

33. See, also Walker (2012). Walker distinguishes the information that someone would need "in order to be able to consent (the term 'informed consent' here is simply a way of indicating that consent requires a certain amount of information)" from the information that he "might want or need in order to come to an informed choice about whether to consent" (2012: 59-60). Again, in the former case Walker is referring to what is needed for valid consent. 
sent the position or policy of the National Institutes of Health, U.S. Public Health Service, or the Department of Health and Human Services.

\section{References}

Alexander, Larry (1996). The Moral Magic of Consent (II). Legal Theory, 2(3), 165-174. https://doi.org/10.1017/S1352325200000471

Alexander, Larry (2014). The Ontology of Consent. Analytic Philosophy, 55(1), 102-113. https://doi.org/10.1111/phib.12035

Alexander, Larry, Heidi Hurd, and Peter Westen (2016). Consent Does Not Require Communication: A Reply to Dougherty. Law and Philosophy, 35(6), 655-66o. https:// doi.org/10.1007/s10982-016-9267-z

Bach, Kent (2012). Saying, Meaning, and Implicating. In K. Allan and K. Jaszczolt (Eds.), Cambridge Handbook of Pragmatics (47-68). Cambridge University Press. https://doi. org/10.1017/CBO9781139022453.004

Bok, Sissela (1995). Shading the Truth in Seeking Informed Consent for Research Purposes. Kennedy Institute of Ethics Journal, 5(1), 1-17. https://doi.org/10.1353/ken.0.0116

Brock, Dan W. (2008). Philosophical Justifications of Informed Consent in Research. In Ezekiel J. Emanuel, Christine Grady, Robert A. Crouch, Reidar K. Lie, Franklin G. Miller, and David Wendler (Eds.), The Oxford Textbook of Clinical Research Ethics (606612). Oxford University Press.

Bromwich, Danielle (2015). Understanding, Interests and Informed Consent: A Reply to Sreenivasan. Journal of Medical Ethics, 41(4), 327-331. https://doi.org/10.1136/ medethics-2013-101499

Bromwich, Danielle and Joseph Millum (2015). Disclosure and Consent to Medical Research Participation. Journal of Moral Philosophy, 12(2), 195-219. https://doi. org/10.1163/17455243-4681027

Bromwich, Danielle and Joseph Millum (2017). Informed Consent to HIV Cure Research. Journal of Medical Ethics, 43(2), 108-113. https://doi.org/10.1136/medethics2015-103122

Council for International Organizations of Medical Sciences (CIOMS) (2016). International Ethical Guidelines for Health-related Research Involving Humans (4th ed.). Geneva.

Dougherty, Tom (2015). Yes Means Yes: Consent as Communication. Philosophy \& Public Affairs, 43(3), 224-253. https://doi.org/10.1111/papa.12059

Eyal, Nir (2014). Using Informed Consent to Save Trust. Journal of Medical Ethics, 40(7), 437-444. https://doi.org/10.1136/medethics-2012-100490

Faden, Ruth R. and Tom L. Beauchamp (with Nancy M. P. King) (1986). A History and Theory of Informed Consent. Oxford University Press.

Grice, H. Paul (1957). Meaning. Philosophical Review, 65(3), 377-388. https://doi. org/10.2307/2182440

Grice, H. Paul (1989). Studies in the Ways of Words. Harvard University Press.

Healey, Richard (2015). The Ontology of Consent: A Reply to Alexander. Analytic Philosophy, 56(4), 354-363. https://doi.org/10.1111/phib.12070

Hurd, Heidi (1996). The Moral Magic of Consent. Legal Theory, 2(2), 121-146. https://doi. org/10.1017/S1352325200000434 
Manson, Neil C. and Onora O'Neill (2007). Rethinking Informed Consent in Bioethics. Cambridge University Press. https://doi.org/10.1017/CBO9780511814600

Miller, Franklin G. and Alan Wertheimer (2010). Preface to a Theory of Consent Transactions: Beyond Valid Consent. In Franklin G. Miller and Alan Wertheimer. The Ethics of Consent: Theory and Practice (79-105). Oxford University Press.

O'Neill, Onora (2002) Autonomy and Trust in Bioethics. Cambridge University Press. https://doi.org/10.1017/CBO9780511606250

Ripstein, Arthur (2009). Force and Freedom: Kant's Legal and Political Philosophy. Harvard University Press. https://doi.org/10.4159/9780674054516

Saul, Jennifer M. (2002). Speaker Meaning, What is Said, and What is Implicated. Noûs, 36(2), 228-248. https://doi.org/10.1111/1468-0068.00369

Searle, John (1975). Indirect Speech Acts. In P. Cole and J. Morgan (Eds.), Syntax and Semantics: Speech Acts (Vol. 3, 59-82). Academic Press.

Sreenivasan, Gopal (2003). Does Informed Consent to Research Require Comprehension? Lancet, 362(9400), 2016-2018. https://doi.org/10.1016/S0140-6736(03)15025-8

Stalnaker, Robert (2002). Common Ground. Linguistics and Philosophy, 25(5), 701-721. https://doi.org/10.1023/A:1020867916902

Tartt, Donna (2004). The Secret History. Random House.

Walker, Tom (2012). Informed Consent and the Requirement to Ensure Understanding. Journal of Applied Philosophy, 29(1), 50-62. https://doi.org/10.1111/j.1468-5930.2011.00550.x

Wendler, David and Christine Grady. (2008). What Should Research Participants Understand to Understand they are Participants in Research? Bioethics 22(4), 203-208. https://doi.org/10.1111/j.1467-8519.2008.00632.x

Wertheimer, Alan (2003). Consent to Sexual Relations. Cambridge University Press. https:// doi.org/10.1017/CBO9780511610011

World Medical Association (2013). Declaration of Helsinki: Ethical Principles for Medical Research Involving Human Subjects. Fortaleza, Brazil. 